\title{
A Study of English Translation of Colloquial Expressions in Two Translations of Jamalzadeh: Once Upon a Time and Isfahan Is Half the World
}

\author{
Elham Jalalpour \\ English Department, Islamic Azad University, Isfahan (Khorasgan) Branch, Iran \\ Hossein Heidari Tabrizi \\ English Department, Islamic Azad University, Isfahan (Khorasgan) Branch, Iran
}

\begin{abstract}
The purpose of this study was to explore the translation of one of the sub-categories of culturebound items that is colloquial and slang expressions from Persian to English in two works by Jamalzadeh, Yeki Bud, Yeki Nabud translated by Moayyed \& Sprachman and Sar o Tah e Yek Karbas translated by Heston. Applying Newmark's (1988b) framework, the type and frequency of translation procedures applied by translators as well as the effectiveness of the translators in preserving the level of colloquialism of source texts were determined. The results of this descriptive study revealed that the translators had applied 6 procedures: synonymy (\% 51), paraphrase (\% 26.5), literal $(\% 8.5)$, descriptive equivalent $(\% 2.5)$, couplet $(\% 2)$, shift $(\% 1)$, omission (\%5) and mistranslation (\%3.5). As for maintaining the informal style of the source texts, the cotranslators of the book of Yeki, Sprachman (native English translator) and Moayyed (native Persian translator) have been more consistent and successful in preserving the tone of the original text than Heston (native English translator of Sar). This success can be partly justified by the acquaintance of Moayyed with Persian language and culture making the correct recognition and translation of expressions possible.
\end{abstract}

Index Terms - translation, colloquialism, Newmark, culture, equivalent

\section{INTRODUCTION}

Colloquial expressions are among the cultural elements of a society that may get the translator into trouble while rendering them. How can he/she render them to redefine the author's intended meaning successfully? Sometimes, the researcher has faced some translated texts that their colloquial expressions could be rendered in a better way to be more comprehensible for the target audience and could transfer the author's intention in a more appropriate way.

Conveying what the source language writer or speaker means is a crucial matter in translation studies. Based on the nature of some writings or even style of writers, a number of colloquial expressions may be found in various texts that make them specific from the translation point of view. Unfortunately, misunderstanding of colloquial expressions in different texts has resulted in bad and sometimes awful translations that could not meet the expectations of the target language reader and fall short of expectations of the critics. The purpose of the present study is to study the way the selected Persian-English translators have treated colloquial expressions, the degree to which they used Newmark's procedures, and finally the effectiveness of the translators in transferring the colloquial/slang words and expression in terms of preserving both meaning and register that is the informal tone.

\section{LITERATURE REVIEW}

\section{A. Language Varieties}

Ratnan Ingrum (2009, pp.37-39) has divided the language varieties into the following sub-categories:

a. Standard Language: Standard language is mainly used for educational and governmental aims. Trudgill (1992, p.70 in Ratnan Ingrum, 2009) argues that "standard language is the variety of English which is usually used in printed from, is spoken by educated native speakers and which is normally taught in schools and to non-native speaker learning the language".

b. Cant: Cant is used for occupational and secretive purposes. Cant refers to the limited, technical words and expression of any specific group, commonly used by underworld group (criminal, tramps and beggar, etc). As a result, it is often called "thieves" or "underworld" slang. When the underworld wants to talk or to communicate among themselves secretly, they use a kind of language that is 'secret language'. These expressions are not found in the slang language.

c. Jargon: Jargon refers to a collection of expressions used by one social or occupational group that are not used and regularly not understood by the public. Hence, all professional terminologies, such as medical, law and engineering are 
qualified as jargon because these terminologies offer terms, which are unfamiliar to general population, for instance, the terms "bilateral perobital haematoma" in medical, "in absentia" in law, and "gasket" in engineering field.

c. Glossolalia: An example of using a language version for religious purposes is the choice of glossolalia of "speaking in tongue" used by certain charismatic Christian groups.

As far as the position of colloquialism in this classification is concerned, Dalzell (1998 in Weeks, 2010) claims that "there is a huge overlap between slang and colloquial and regional" so that "some would argue that cool is no longer slang but is so commonly used as to have lost the identity value and so is merely colloquial."

Taking this into account, the colloquial expressions identified in the source books may include the slangs as well. However, it is worth mentioning that the colloquial expressions were checked in the Persian Dictionary of Colloquialism by Jamalzadeh (2003) and Najafi (2008).

\section{B. Definition of Colloquialism}

The word "colloquialism" stems from the Latin colloquium that means "conference" or "conversation." Colloquialism-as a literary device- implies using informal or everyday language in literature. Colloquialisms have generally a geographic nature, as a result, every colloquial expression belongs to a regional or local dialect (Literary Devices, n.d)

Leech and Svartvik (1975, p.24 in Sukspiroj, 2009) regard the colloquial language as the equivalent of the umbrella term of informal language calling it the first form of language that a native speaking child becomes familiar with. As they argue, since the comprehension of the informal or colloquial language is easier compared to formal language, it is now used for some certain public communications such as newspapers and advertisements.

In general, a colloquialism is any informal word or expression used aptly in conversation among ordinary or educated people (Nofalli, 2012).

A colloquialism is "a word, phrase, or other form used in informal language. Dictionaries often display colloquial words and phrases with the abbreviation colloq. as an identifier" (Colloquialism, n.d).

In the same vein, Trask (1999 in colloquialism, n.d.) argues that:

"colloquial language, colloquial dialect, or informal language is a variety of language commonly employed in conversation or other communication in informal situations. The word colloquial by its etymology originally referred to speech as distinguished from writing, but colloquial register is fundamentally about the degree of informality or casualness rather than the medium, and some usage commentators thus prefer the term casualism".

According to McCrimmon (1963, p.169), the word "colloquial" has been defined by the American College Dictionary as "characteristic of or appropriate to ordinary or familiar conversation rather than formal speech or writing." In his opinion, this definition does not mean that a colloquial word is improper or inappropriate or careless. McCrimmon (1963) himself calls colloquialism any word or expression that may accurately be used in conversation among educated persons. He maintains that such definition of colloquial word transforms it to a wider term than popular words or idioms covering the popular words and idiomatic constructions as well. They also include constructions that are not strictly idioms, particularly abbreviated or clipped versions of more formal words, such as 'ad' for 'advertisement (in Barzegar, 2008).

\section{Usage of Colloquialism}

Colloquial language is different from formal speech or formal writing (Colloquialism, n.d.). It is a category of language that speakers normally use when they are stress-free and not especially self-conscious (Trask, 1999 in Colloquialism, n.d.).

Some colloquial speech includes a large amount of slang while some has no slang at all. Slang is allowable in colloquial language without being a necessary constituent. Other examples of colloquial usage in English are contractions or swearword. In the philosophy of language, the term "colloquial language" refers to ordinary natural language that is distinct from specialized forms applied in logic or other areas of philosophy (Davidson, 1997 in Colloquialism, n.d.). In the field of logical atomism, meaning is appraised in a different way than with more formal propositions (Colloquialism, n.d.).

\section{Features of Colloquialism}

According to Barzegar (2008) in terms of the scale of formality, colloquial language is a higher style than slang being different from the formal standard language in terms of pronunciation, choice of word, and sentence structure.

Holmes (1992, p. 265 in Barzegar, 2008) enumerates pronunciation and grammatical features as two linguistic features of colloquial style in English:

\section{$\sqrt{ }$ Pronunciation Features}

[h]- dropping, e.g. Oh well, 'e said, 'I suppose you can 'ave it.

[in] (vs. formal [ing], e.g. We was up there cuttin'.

$\sqrt{ }$ Grammatical Features

Was with plural subject we, e.g. we was up there cutting.

Come (vs. came): Frazer come on to us.

\section{E. Classification of Colloquialism in English Language}


Colloquialism is classified into three sub-categories that are words, phrases, and aphorisms. If the words reflect the regional dialect of the speaker, they can be qualified as colloquialism examples, or if they are contractions or examples of swearword. Phrases and aphorisms are colloquialisms if they are not used in literal sense, nevertheless, are broadly understandable within a geographical region (Literary Devices, n.d.).

\section{Words:}

- Regional differences: One well-known colloquial variance in the United States is the way an individual refers to a carbonated beverage. There are regional boundaries that isolates the usage of the words "soda", "pop", "soft drink", and "Coke" (used as a generic term and not just to refer to the brand). There are many differences between American English and British English, such as "truck"/“lorry", "soccer"/“football”, and "parakeet”/“budgie".

- Contractions: Words such as "ain't" and "gonna" that are not used widely throughout English-speaking communities are some notable illustrations of colloquialism.

- Profanity: A set of words are deemed irreverent in some dialects of English where they are not at all immoral or swearword in other dialects. For example, the word "bloody" is a simple adjective in American English, but is a swearword in British English.

\section{Phrases:}

The following phrases all are qualified as colloquialism:

- Old as the hills

- Penny-pincher

- She'll be right (Australian English, meaning everything will be all right)

- Pass the buck

- Eat my dust

\section{Aphorisms:}

The following aphorisms all are qualified as colloquialism:

- I wasn't born yesterday.

- There's more than one way to skin a cat.

- Put your money where your mouth is.

- You're driving me up the wall (Literary Devices, n.d.).

McCrimmon (1963, pp.32 in Nofalli, 2012) has categorized the colloquial English in the following way:

1. Relatively short simple sentences, often grammatically incomplete, with few rhetorical devices;

2. An extravagant usage of contractions (I'll, we've, didn't, can't), clipped words (cab, exam, phone), and the omission of relative pronouns (who, which, that) which would be preserved in a formal style;

3. A vocabulary marked by general prevention of learned words and by inclusion of some less offensive slang terms;

4. A simplified syntactic structure that leans heavily on idiomatic units and occasionally neglects the fine differences of formal grammar and;

5. A personal or familiar tone, which intends to create the impression of talking warmly and friendly to the readers.

\section{F. Jamalzadeh as a Pioneer in Using Colloquialism in Persian Literature}

According to Kamshad and Mozaffari (2008, in Encyclopedia Iranica), Jamalzadeh has a singular position in the history of modern Persian literature. As an innovator of the modern literary language, he was the first person who introduced the techniques of European short-story writing in Persian literature. According to them,

"the particular and conscious employment of language in the stories is a departure from the traditional styles of prose writing in Persian. The language of the narrative is direct, simple, and colloquial, and the selection of words varies based on the class and educational level of the characters." (Kamshad and Mozaffari, 2008, in Encyclopedia Iranica)

Researchers properly trace the origin of this kind of language to the newspapers of the constitutional epoch, principally to ironic essays and poetry of Dehkhoda in the Charand parand column in Sur-e Esrafil and the poetry of Sayyed Ashraf-al-Din in Nasim-e shemal. To highigh the importance of the colloquial language, Jamalzadeh has brought a dictionary of colloquial Persian words and phrases in the end of his books- Yeki bud, Yeki nabud. He continued collecting and documenting the colloquial words and expressions throughout his life. The collection obtained from his efforts was later published as a book in 470 pages entitled Farhang-e loghat-e amiana (Dictionary of Colloquial Words) (ibid).

\section{G. Previous Works on the Translation of Colloquial Expressions}

Reviewing the relevant literature using library and online sources, the researcher found some national and foreign studies conducted on the translation of colloquial expressions in general and the translation of Jamalzadeh's works in terms of different aspects, in particular.

For the former, the following theses and studies were identified:

Mahdavi Zafarghandi and Falahatdoost (2013) conducted a comparative study of English colloquial language utterances in novel translation from English to Persian employed by the translators. In addition to some cases of mistranslated items and translating into a higher degree of formality, they found that different strategies have been applied by the translators. 
In his M.A. thesis, Nofalli (2012) analyzed the translation of the slang words and jargon found in "Transformers" movie. According to the results of this study, to produce a good translation, the translator should have sufficient knowledge about slang, jargon and colloquial expressions and also understand the method in translating the source language into the target language to get a good translation. In this way, the target readers will comprehend and get the idea and meaning of the original text.

Shadrah (2010) for his M.A thesis analyzed the colloquial expressions in one children's story book named "The Secret Life of MS WIZ' written by Terence Blacker. The main purposes of this study were to identify the types of colloquial expression, and to discover the translation techniques applied by the translator for translating the colloquial expression.

Nikroo (2004) in her M.A paper explored the English translation of Persian colloquial language in "Modier $e$ Madreseh" by Jalal Al Ahmad so as to identify the translation procedures applied by the translator for the transference of the colloquial expressions into English language.

The last but not the least, Bakhtiari (2001) in one comparative study, explored the translation strategies applied for the translation of the colloquial expressions in the English subtitles of the post-revolutionary Iranian films and found that "translation by synonymy" and "omission" were the most frequent strategies used by the translator of the films in question.

For the latter group that is studies conducted on the Jamalzadeh's works from the viewpoint of translation, two theses were identified:

1. Aminzadeh (2011) analyzed the strategies in two English translations of Yeki Bud, Yeki Nabud by Moayyad and Sprachman and Bashiri and reported that the translators have applied all strategies proposed by Newmark. In addition, it was found that the first strategy, reproducing the same image in the target language, and second strategy that was reproducing the source image using a standard target language image conforming with the target language and culture, had been used more than others.

2. Pishbin (2011) explored the strategies used by the translators for the transference of the idioms and proverbs in two works by Jamalzadeh that is Yeki Bud, Yeki Nabud and Sar o Tahe Yek Karbas based on Baker's theoretical model and found that using an idiom with similar form and meaning and an idiom with similar meaning but different form were the most frequent strategies applied.

However, to the best of the researcher's knowledge, no similar research has been conducted on Jamalzadeh's works from the viewpoint of the translation of the colloquial expressions.

Based on the aforementioned issues, this research tried to find the procedures applied by the translators and their frequency in the first place and to find which translator that is native Persian translator or native English translator has been more successful in the correct transference of the colloquial expressions of the source texts.

\section{Methodology}

\section{A. Research Design}

The present study was based on the descriptive framework building on the theory of descriptive translation studies(DTS). According to Holmes (1988, p. 71), DTS mainly deals with "describing the phenomenon of translating and translation as they manifest themselves in the world of our experiences". DTS has three aspects which include: 1) the examination of the product of translation, 2) the function of translation, 3) the process of translation. Accordingly, the focus of the present research is on the product of the translation which is limited to the colloquial expressions.

The unit of analysis in this research was every sentence which was identified to be colloquial or slang in full form or contain colloquial expressions/slang words by referring to the Persian were Persian and English, respectively.

\section{B. Materials}

The data of this research are taken from two works by Jamalzadeh (1892-1997) entitled Yeki Bud, Yeki Nabud (1921) and Sar o Tah e Yek Karbas (1956) translated by Moayyed and Sprachman (1985) and Heston (1983), respectively.

\section{Theoretical Framework}

Colloquial expressions belong to the culture-bound concepts category since they have root in the culture of their users. The following are the different translation procedures that Newmark (1988b pp. 82-91 in Ordudari, 2007) proposes for this category of language items:

- Transference: transference of an SL item to the TL text. It also includes transliteration. (e.g. online: آناين online ; Pop culture: فر هنگ صٍ : farhang e pop)

- Naturalization: adapting the SL word firstly to the normal pronunciation, then to the normal morphology of the TL. (e.g. doctor: دكتر doctor ; decoration: دكور اسيون decoration)

- Cultural equivalent: replacing a cultural word in the SL with a TL equivalent. However, "they are not accurate". (e.g. church: مسجد Masjed ; وضوVozu: Ablution)

- Functional equivalent: using a culture-neutral word. (e.g. "lean beef" : كوشت كم جربى goosht e kam charbi)

- Descriptive equivalent: explaining the meaning of the culture-bound terms in several words. (e.g.Mash: to pull your wet hand on the surface) 
- Componential analysis: comparing an SL word with a TL word which has a similar meaning but is not a clear oneto-one equivalent, by illustrating their similar sense components in the first place and their different ones in the second place."

- Synonymy: using "near TL equivalent." In this case, economy outplays accuracy. (e.g.قشقره بريا كردن Gheshghereh barpa kardan : to holler)

- Through-translation: using the literal common translations of collocations, names of organizations and institutions and components of compounds. It is also can be called: calque or loan translation. (e.g.g.ورد آ سرت avardam: I made your head ache)

- Shifts or transpositions: changing the grammar from of the SL, for example, (1) changing the singular to plural, (2) changing the SL structure where a it does not exist in the TL, (3) changing the SL verb to a TL word, changing an SL noun group to a TL noun and etc.. (e.g. shoes (plural): كفش Kafsh (singular)

- Modulation: reproducing the meaning of the source text by complying with the present norms of the target language,

- Recognized translation: using the formal or the normally accepted translation of the institutional words and terms."(e.g. NASA :e.g. ناسا NASA)

- Compensation: compensating for the loss of meaning in one section of a sentence in another section.

- Paraphrase: Explaining the meaning of the culture-bound terms that is much more comprehensive compared to descriptive equivalent.(e.g. بر و بيا داثتن Bor o bia dashtan: made a name for oneself)

- Notes: Providing the additional information required can be done using 'footnotes.' Though some stylists believe that adding footnotes makes the appearance of the translation unpleasant, however, they can produce a better reproduction of the content of the source text. According to Nida (1964, pp.237-39 in Ordudari, 2007 footnotes are commonly used for two purposes: (1) providing complementary information, and (2) highlighting the original's discrepancies.

\section{Procedures}

This study was conducted based on the following steps:

1. Perusing the source texts for finding and extracting the colloquial expressions including the slang expression;

2. Perusing the target texts for identifying and extracting the equivalents applied by the translators for the items under study;

3. Finding the kind of procedures applied by the translators based on the theoretical framework used in the study;

4. Tabulating the data in order to have a more coherent and comprehensive picture of them and facilitate the process of data analysis;

5. Calculating the frequency of the applied procedures as well as their percentages and presenting them in tables.

It's worth mentioning that after giving a number of examples for elucidating the way of analyzing, the remaining data were tabulated. The colloquial expressions were also categorized based on the translation procedure applied in order to have a more coherent and unified picture of them.

\section{RESULTS}

\section{A) Translation by Synonymy}

Definition: using the "near TL equivalent." In this case, economy outplays accuracy. (Newmark, 1988 b, p.84 in Orduradri, 2007)

ST: و فارسى ر انستا حسيني باش حرف بزنم (ص. Farsi e rasta hosseini bash harf ebzanam)

TT: That I was even speaking honest-to-God Persian with him (p.41).

\section{B) Translation by Paraphrase}

Definition: In this procedure the meaning of the culture-bound term is explained. Here the explanation is much more detailed than that of descriptive equivalent. (Newmark, 1988b, p.91)

ST: انسان هر شب خدا، خانه غير كيه مرك بكذارد (ص.120) (Ensan har shab e khoda khane e gheyr kapeye marg bogozarad)

TT: For one to spend every blessed night in someone else's home (p.103)

According to Jamalzadeh's Dictiornary of Colloquial Expressions (2003, p. 165), /rasta hoseini/ is a Persian colloquial expression which is used it is desired to emphasize that something is really true. The equivalent used by the translators for this expression is /honest-to-God/ which according to the Oxford Advanced Learner's Dictionary (2005, p. 623) is an informal expression used to emphasize that saying is true. By a comparison of two equivalents considering Newmark's model, it can be infer that the procedure is synonymy.

\section{C) Translation by Couplet}

Definition: It occurs when the translator combines two different procedures. (Newmark, 1988b, p.91 in Ordudari, 2007)

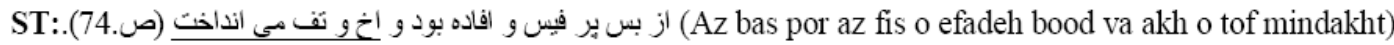

TT: who fussed and primped, spat "akh" in disgust (p.69).

The Persian colloquial expression of /akh o tof andakhtan/ means "to spat" which is used for showing disgust (Jamalzadeh, 2003, p. 49) An examination of the English translation shows that the translators have used a combination of literal translation plus paraphrase that has been referred to as "Couplet" procedure in Newmark's model. 


\section{D) Literal (Through) Translation}

Definition: using the literal common translations of collocations, names of organizations and institutions and components of compounds. Its other names are "calque or loan translation". (Newmark, 1988b, p.84 in Ordudari, 2007)

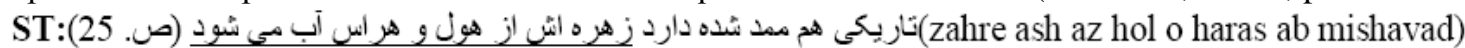

TT: Ramazan's resolve was about to melt away (p. 36).

/zahre ab shodan/ is a Persian colloquial expression showing "great fear" (Jamalzadeh, 2003, p. 185). Looking at the English equivalent, it gets clear that the translators have opted for literal translation for this item.

\section{E) Translation by Shift or Transposition}

Definition: changing the grammar from of the SL, for example, (1) changing the singular to plural, (2) changing the SL structure where a it does not exist in the TL, (3) changing the SL verb to a TL word, changing an SL noun group to a TL noun and etc.

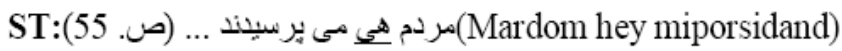

TT: The people kept asking me ...(p.54).

F) Translation by Omission

Definition: According to Ivacovoni (2000), omission means dropping a word or words from the SLT while translating that may occur due to culture clashes between the SL and TL.

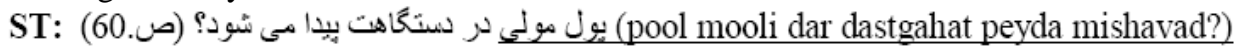

TT: And a bit of change has came your way (p.57).

\section{G) Descriptive equivalent}

ST: يك سولداني بود كه اسمش را مطبخ كذاشته بود. (صل61) (yek sooldani bood ke esmesh ra matbakh gozashte bood)

TT: A dark little place they called a kitchen. (p.30)

As per Jamalzadeh (2003, p. 189), /suldani/ is a colloquial word that means "a very dark and dirty place". As it is obvious, the translator has rendered this word using descriptive equivalent of course without keeping its informal tone.

\section{H) Mistranslation}

Definition: Lung (1998 in Rahekhoda, 2010) has defined mistranslation as "any distortion of meaning as a result of misunderstanding the text or a conscious decision to skip translating at all. Mistranslation occurs as a result of various factors such as unfamiliarity with the source culture.

ST: مردم كيب تا كيب روبى صندلى نشستَه بودند (ص.49) (Mardom kip ta kip rooye sandal neshahste boodand)

TT:There were more stuffed shirts that you couldn't shake a stick at (p.49).

According to Jamalzadeh (2003, p. 432), /kip ta kip/ is a colloquial expression which means "full of, completely occupied without any free space". The equivalent used by the translators is "stuffed shirt" which is an informal noun meaning "a person who is very serious, formal, boring or old-fashioned" (Oxford, 2005, p. 1293) which is a wrong equivalent for this item.

As a colloquial expression, /hey/ in this sentence acts as an adverb for showing the continuity of the action. However, to transfer its meaning, it has been replaced by "kept" in the verb form that is accompanied by a shift in the grammatical category. Accordingly, it can be concluded that the procedure used here is shift.

In this section, statistical results gained from data analysis will be presented in the form of tables and diagrams. To do so, the frequency of the applied translation procedures was counted separately for the each and every procedure. The frequency refers to the total number of items translated by using each procedure and the percentage indicates the percentage proportion of each procedure. However, discussing and elaborating on them in more details will come in the next sub-section. The results have been categorized separately for each book.

As it is clear, the first table represented in this section has been devoted to the frequency and percentage of the procedures identified for the data extracted from the book of Yeki which were 87 cases in total:

TABLE 4-9

FREQUENCY OF THE PROCEDURES APPLIED TO THE TRANSLATION OF COLLOQUIAL EXPRESSIONS EXTRACTED FROM YEKI BUD, YEKI NABUD

\begin{tabular}{|l|l|l|}
\hline Translation Procedure & Frequency & Percentage (\%) \\
\hline Synonymy & 45 & 51.72 \\
\hline Paraphrase & 27 & 31.03 \\
\hline Omission & 5 & 5.74 \\
\hline Mistranslation & 4 & 4.59 \\
\hline Couplet & 2 & 2.29 \\
\hline Literal & 2 & 2.29 \\
\hline Shift & 2 & 2.29 \\
\hline Total & $\mathbf{8 7}$ & $\mathbf{1 0 0}$ \\
\hline
\end{tabular}

To obtain a more clear-cut picture of the results, the bar diagram related to the frequency table obtained for Yeki presented in Table no. 1 has also been depicted which has been shown in figure no. 1 as it follows: 


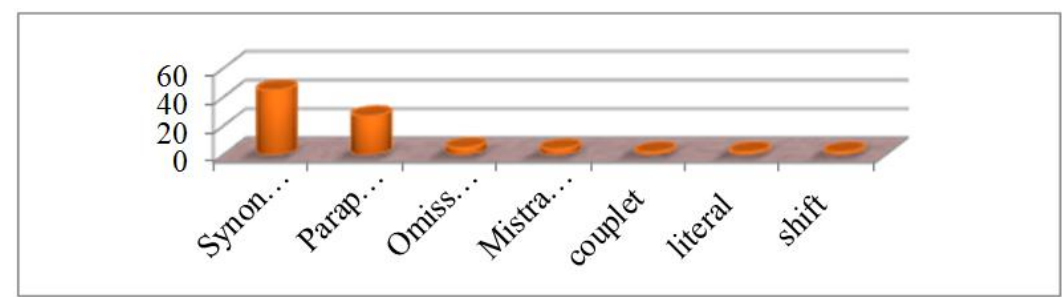

Figure 1-Frequency of the Procedures Applied to the Translation of Colloquial Expressions Extracted from Yeki Bud, Yeki Nabud

Following steps similar to those used for the book of Yeki, the frequency as well as the percentage of the procedures obtained for the transference of the total 113 colloquial/slang words and expression related to the book of Sar have been calculated and summarized in Table no.2:

TABLE 2

FREQUENCY OF PROCEDURES APPLIED TO THE TRANSLATION OF COLLOQUIAL EXPRESSIONS EXTRACTED FROM SAR O TAH E YEK KARBAS
\begin{tabular}{|l|l|l|}
\hline Translation Procedure & Frequency & Percentage $(\%)$ \\
\hline Synonymy & 57 & 65.51 \\
\hline Paraphrase & 26 & 29.88 \\
\hline Literal & 15 & 17.24 \\
\hline Descriptive Equivalent & 5 & 5.74 \\
\hline Omission & 5 & 5.74 \\
\hline Mistranslation & 3 & 3.44 \\
\hline Couplet & 2 & 2.29 \\
\hline Total & $\mathbf{1 1 3}$ & $\mathbf{1 0 0}$ \\
\hline
\end{tabular}

The bar diagram related to the frequency table of the book of Sar has been depicted below, as well:

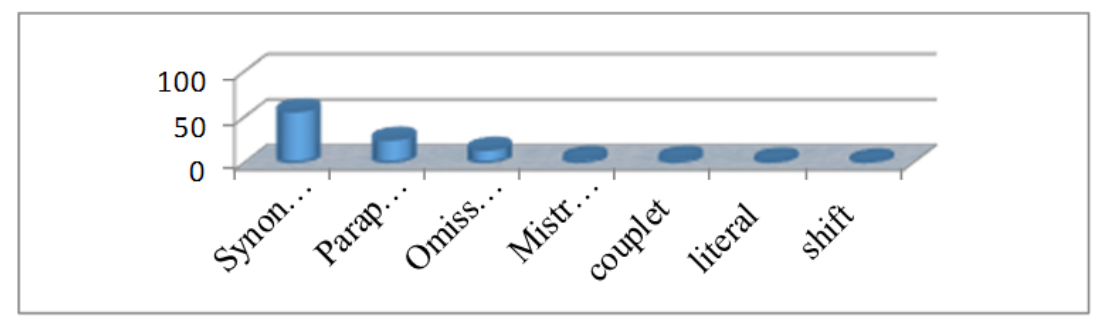

Figure 2- Frequency of Procedures Applied to the Translation of Colloquial Expressions Extracted from Sar o Tah e Yek Karbas

To have an overall picture of the performance of the translators of the two books allowing drawing general conclusions, Table no. 3 was created. To create this table, the sum value for the frequency of every single procedurecommon and uncommon in both translations - besides the respective percentage values were calculated by the researcher:

TABLE 3

FREQUENCY PERCENTAGE OF PROCEDURES APPLIED TO THE TRANSLATION OF COLLOQUIAL EXPRESSIONS EXTRACTED FROM THE TWO BOOKS

\begin{tabular}{|l|l|l|l|}
\hline Translation Procedure & Yeki & Sar & Percentage\% \\
\hline Synonymy & 45 & 57 & 51 \\
\hline Paraphrase & 27 & 26 & 26.5 \\
\hline Literal & 2 & 15 & 8.5 \\
\hline Descriptive Equivalent & 0 & 5 & 2.5 \\
\hline Omission & 5 & 5 & 5 \\
\hline Mistranslation & 4 & 3 & 3.5 \\
\hline Couplet & 2 & 2 & 2 \\
\hline Shift & 2 & 0 & 1 \\
\hline Total & $\mathbf{8 7}$ & $\mathbf{1 1 3}$ & $\mathbf{1 0 0}$ \\
\hline
\end{tabular}

Figure no. 3 which shows a pie diagram of the data represented in Table no. 3 makes it possible to come to a general inference about the translation conditions governing the translation of colloquial/slang expressions in terms of the procedures applied and their proportion.

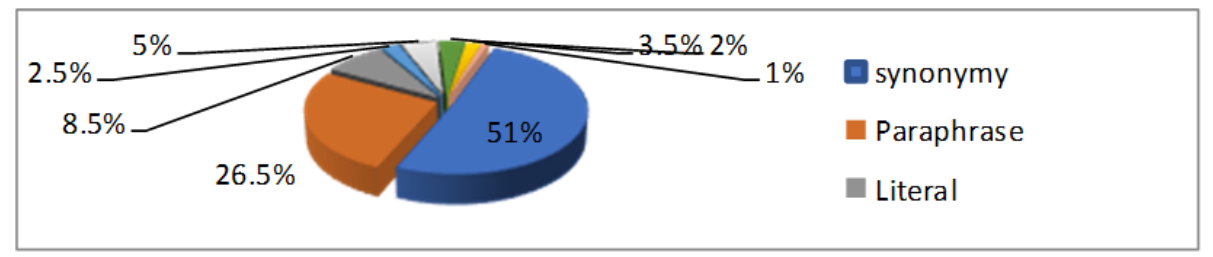

Figure 3- Frequency percentage of Procedures Applied to the Translation of Colloquial Expressions Extracted from the two Books 
Considering the research questions outlined in this paper, it was also necessary to determine the ratio of formal to informal English equivalents used in the TTs in question. The results for two books have been represented in the following table:

TABLE 4

FREQUENCY OF FORMAL VS. INFORMAL TRANSLATION EQUIVALENTS IN BOTH TRANSLATIONS

\begin{tabular}{|l|l|l|l|}
\hline Book & Degree of Formality & Frequency & Percentage (\%) \\
\hline \multirow{3}{*}{ Yeki Bud , Yeki Nabud } & Formal & 26 & $\% 32$ \\
\cline { 2 - 4 } & Informal & 56 & $\% 68$ \\
\cline { 2 - 4 } & Total & 82 & $\% 100$ \\
\hline \multirow{3}{*}{ Sar o Tah e Yek Karbas } & Formal & 90 & $\% 83$ \\
\cline { 2 - 4 } & Informal & 18 & $\% 17$ \\
\cline { 2 - 4 } & Total & 108 & $\% 100$ \\
\hline
\end{tabular}

Figure no.4 represents the bar diagram related to Table no.4. This facilitates the comparison process of the translators with regard to their success in preserving the original tone of the STs.

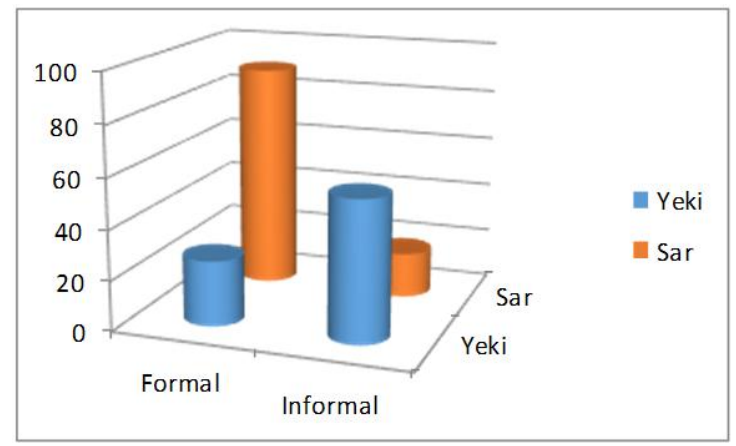

Figure 4- Frequency of Formal vs. Informal Translation Equivalents in both Translations

In Table no.5, the frequency and percentage of formal vs. informal equivalents have been shown for each book, separately. To draw general conclusion on the translation quality in terms of preserving the informal style of the STs, it was also necessary to obtain the total ratio of formal to informal English equivalents by calculating their sum. The respective results have been presented in the following table:

TABLE 5

OVERALL FREQUENCY PERCENTAGE OF FORMAL VS. INFORMAL EQUIVALENTS IN BOTH TRANSLATIONS

\begin{tabular}{|l|l|l|l|l|}
\hline Degree of Formality & Yeki & Sar & Total & $(\%)$ \\
\hline Formal & 26 & 90 & 116 & 61 \\
\hline Informal & 56 & 18 & 74 & 39 \\
\hline Total & 82 & 108 & 190 & 100 \\
\hline
\end{tabular}

Finally, in no.5, a pie diagram has been depicted facilitating the process of comparison.

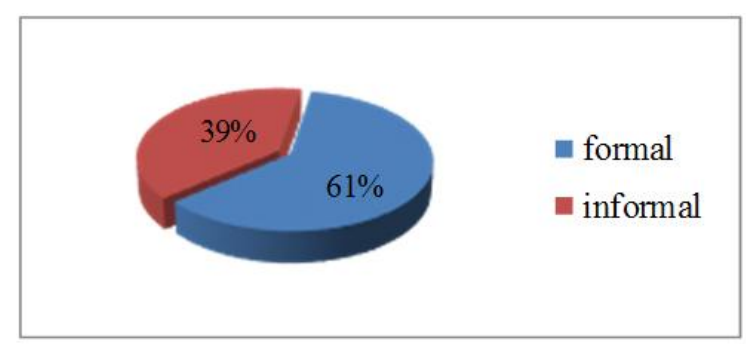

Figure 5- Overall Frequency Percentage of Formal vs. Informal Equivalents in both Translations

\section{DISCUSSION}

\section{A. Addressing Research Question One}

As stated earlier, the first question is as follows: What translation procedures have been applied by translators for the transference of colloquialism of Jamalzadeh's works?

As per Table no.1, the procedures applied by the translators for the transference of colloquial expressions in the book of Yeki were: a) Synonymy b) Paraphrase, c) Couplet, d) Literal translation and e) Shift or transposition c) Ommision and d) Mistranslation. 
In the same vein, as it is evident from Table no.2, the following procedures have been used by the translator for rendering the colloquial items in the book of Sar: a) Synonymy, b)Paraphrase, c) Literal translation, d) Descriptive equivalent and e) Couplet, f) Ommision, and Mistranslation.

It is worth mentioning that all these procedures are among the procedures suggested by Newmark except two ones that is ommision and mistranslation. According to Ivacovoni (2000), omission means dropping a word or words from the SLT while translating that may occur due to culture clashes between the SL and TL. Lung (1998) defines mistranslation as any distortion of meaning as a result of misunderstanding the text or a conscious decision to skip translating at all. It is noteworthy that mistranslation occurs as a result of various factors such as unfamiliarity with the source culture.

\section{B. Addressing Research Question Two}

The second question this paper tried to answer was as follows: "Which procedure/procedures has/have been used more frequently and why?"

Similar to the first question, this question was answerable by looking at Tables no. 1 and 2 where the identified procedures together with their frequencies and percentages have been represented.

As for the book of Yeki, use of a synonymy (\%51.72) occupied the first rank followed by paraphrase procedure (\%31.03).The other procedures in terms of frequency were as follows: omission (\%5.74), mistranslation (\%4.59), couplet (\%2.25), literal (\%2.29) and shift (\%2.29).

On the contrary, the most frequently used procedures for the book of Sar were synonymy (\%65.51), paraphrase (\%29.88), literal (\%17.24), descriptive equivalent (\%5.74) and omission (\%3.34), mistranslation (\%3.44) and couplet (\%2.29), respectively.

As the most frequent proceudre identified in both translation, synonymy is a kind of semantic relation. It is used when there is a TL equivalent or near equivalent for a SL word or concept. This can be regarded as an ideal situation by itself reflecting the success of the translators in correct transference of the SL concepts. However, according to Quine (1951 in Shiyab, 2007), synonymy can be subdivided into two categories: "complete synonymy and partial synonymy". Complete synonymy refers to the words whose all components are the same while partial synonymy refers to the words that only some of main components are similar to each other. It is noteworthy that not all the synonymies used by the translators in the target texts in question are of complete synonymy type due to the difference in their register that is level of formality. In detail, in some cases of the synonmies, the translators have decided to sacrifice the connotational meaning for transferring the semantic meaning not preserving the informal tone of the SL words.

Enjoying a relatively similar frequency for both translations (that is \%31.03 vs \%29.88), paraphrase procedure ranked second. Paraphrase aims at preserving the essential meaning of the material that is being translated. Some cases of paraphrasing observed in this study have been inevitable because of the lack of a TL equivalent for a SL term (e.g. /khak bar saram/ paraphrased as "what can I do?"). However, some other cases appeared in the translation have been used only by the free choice of the translators. For example, /haj o vaj budam/ has been translated into /I didn't know what to make of.../ using paraphrase procedure, although it could be replaced by a near synonym that is /stunned/.

The remaining identified procedures were of a much lower frequency compared to the two foregoing elaborated procedures in both translations.

Mistranslated cases observed in this study mainly have been resulted from the lack of a correct understanding of the source concept for the mistranslated ones (e.g. /daste gol be ab dadan/ translated as "throwing that handful of mud we knew about into the water"). The other remaining procedures including literal translation, couplet, shift and descriptive equivalent have occurred either due to a lack of an appropriate equivalent for the source colloquial expressions or merely on the basis of the personal taste and choice of the translators. Absent in the English language and culture, /chador chaqchur/ is a very ideal and prototype example for the former reason that has been rendered literally. It is worth mentioning that literal translation allows the target audience to understand the direct sense of the SL making it possible for the translator to keep close to the original as much as possible and to preserve the meaning without any additional interpretation on the part of the translator (Ulvydienè and Abramovaite, 2012, p. 105). As a final point, an example that can be counted for the latter reason is /cheshm e bad dur/ translated literally as/may the evil eye keep away/. Although there is an informal synonymy for it in English that is /touch the wood/, the translator has opted for literal translation merely on the basis of his personal preference and taste.

\section{Addressing Research Question Three}

Finally, the third question was as follows: "Which translator, that is native Persian translator or native English translator has been effective in the correct transference of the colloquial expressions of the source texts into the target language?"

Considering the fact that the samples examined in this study were colloquial or informal in tone, this question mainly was related to the degree of the success of the translators in preserving the informal tone or register of the original text. To provide a convincing response to this question, the researcher decided to determine the formality of the translation equivalents used by the translators.

As per the results summarized in Table no.4 and diagram no. 4, it can easily be inferred that as co-translators of the book of Yeki, Sprachman (native English translator) and Moayyed (native Persian Translator) have been more 
consistent in preserving the tone of the original text than Heston (native English translator of Sar). To put it differently, the ratio of informal to formal equivalents was $\% 68$ to $\% 32$ and $\% 17$ to $\% 83$ for the book of Yeki and Sar, respectively. This showed that Heston was less successful or effective in reflecting the colloquial or informal tone in most of his selected TL equivalents translating most of them with a higher degree of formality. As a result of this, the intimate tone of the original text has been damaged producing a text with a different tone.

The success of Sparchman and Moayyed (1985) in this regard may be attributed to the familiarity of Moayyed with Persian language and culture which has allowed the recognition of the colloquial expressions available in the source text on the one hand and finding equivalents with similar level of formality for them on the other.

\section{CONCLUSIONS}

Taking an overall look into the whole set of data, the researcher can draw the following final conclusions:

First, no specific criterion was found dominating the use of certain translation procedure for translating the colloquial expressions. The procedures used, were, to some extent, dependent on translators' taste, their knowledge and their faithfulness to the source text.

Second, from among the procedures suggested by Newmark (1988), 6 procedures have been used by the translators for the transference of colloquial expressions from the source texts into the target texts which are as follows, in order of frequency: Synonymy (\%51), paraphrase (\%26.5), literal (\%8.5), descriptive equivalent (\%2.5), couplet (\%2) shift (\%1).

Third, besides the above-mentioned procedures, some cases of omission (\%5) and mistranslation (\%3.5) have also been detected (see Table no. 4.11 and figure no. 4.3.)

Fourth, As far as the preservation of the degree of formality of the source texts that is their informal style is concerned, Table no. 4.13 and figure no.4.5 show that the formal equivalents overweigh the informal ones to a considerably higher extent (\%61 vs. \%39). This finding provides strong evidence on the failure of the translators in reflecting the informal style of the original texts perfectly.

Fifth, regarding the previous note, the researcher would like to assert that translation is just like "painting". As Tverberg (2014) attractively argues, the product of every translation will reflect the overall scene to the audience, however, it won't fully capture the atmosphere of the original text. When another translator re-translates the same text, different nuances will appear. Definitely, some translations will perform better than others while a very bad job is also possible. But, it simply is impossible to completely duplicate this painting using a different palette and different brushes. In the same vein, there are no specific rules regarding how to translate the colloquial words and expressions, hence, it is the task of the translator to make decisions about the priorities at first and select the most appropriate translation procedure (Ulvydienè and Abramovaitè, 2012).

\section{IMPLICATIONS OF THE STUDY}

There are several groups of target audiences who can benefit from this study.

At first, these results can provide novice translators with some general guidance on how to treat and render the colloquial language in the materials being translated. In fact, procedures used by the experienced translators and their strengths and weaknesses in this regard can guide them through their way of translation.

Secondly, the present study has pedagogical values for the lecturers. Both lecturers and language teachers can use the data collection and the outcomes of the study as an input in their classes for the purpose of teaching the translation procedures in a more practical way.

Thirdly, language learners can also take advantage of this research in terms of getting some information regarding the colloquial expressions including their types, their translation-related challenges and the procedures used for their translation. This information may add to their language knowledge.

Finally, the result of this research is expected to open new windows for further future research on colloquialism.

\section{REFERENCES}

[1] Aminzadeh, H. (2011). "A Survey on the Translation of Idioms in Persian Short Stories by Mohammad Ali Jamalzadeh. and its English Counterparts According to the Strategies Introduced By Peter Newmark”. (M.A. thesis paper). English Language Department of Islamic Azad University Central Tehran Branch: Iran.

[2] Bakhtiari, N. (2007). "A Comparative Study of Translation Strategies for the Translation of English Subtitles of Persian Films after the Islamic Revolution”. M.A. Thesis. Isfahan University: Iran.

[3] Barzegar, H. (2008). "Translation of Colloquial Expressions in English-into-Persian Subtitled Films”. Retrieved May 4, 2016, from http://www.translationdirectory.com/articles/article1541.php.

[4] Colloquialism. (n.d.). Retrieved July 18, 2016, from https://en.wikipedia.org/wiki/Colloquialism

[5] Holmes, J. (1963). “An Introduction to Sociolinguistics". London: Longman.

[6] Ivacovoni. A. (2009). Retrieved May 20, 2015, from: http:/translationjournal net./.

[7] Jamalzadeh, M.A. (1982). Yeki Bud, Yeki Nabud (in Persian). Tehran: Arash Publications.

[8] Jamalzadeh, M.A. (1983). Isfahan is Half the World. Heston, W.L. (Translator). United States: Princeton University Press.

[9] Jamalzadeh, M.A. (1985). Once Upon a Time. Moayyad, H \& Sparchman, P. (Translator). New York: Bibliotheca Persica.

[10] Jamalzadeh, M.A. (2003). Sar o Tah e Yek Karbas (Isfahannameh) (in Persian). Tehran: Sokhan Publications. 
[11] Jamalzadeh, M.A. (2004). Colloquial Expressions Dictionary (in Persian). Collected by Mohmad Jafar Mahjoub. Tehran: Sokhan Publications. 2nd Edition.

[12] Kamshad, H. and Mozaffari, N. (2008). JAMALZADEH, MOHAMMAD-ALI ii. Works. Retrieved July 8, 2016, from http://www.iranicaonline.org/articles/jamalzadeh-ii.

[13] Literary Devices, Terms, and Elements. (n.d.). Retrieved July 4, 2016 from http://www.literarydevices.com/colloquialism/.

[14] Najafi, A. (2009). Persian Colloquial Dictionary. Niloofar Publications. $2^{\text {nd }}$ Edition.

[15] Nikroo, S. (2004). "Exploring the English Translation of Persian Colloquial Language in Modier e Madreseh by Jalal Al Ahmad". (M.A paper). Isfahan University. Iran.

[16] Nofalli, T. S. (2012). "Translation Method Used in Translating Colloquial Expressions in Subtitle Text of Transformers Movie. M.A. Paper. Faculty of Humanities Dian Nuswantoro University Semarang. Retrieved July, 16, 2016 from http://eprints.dinus.ac.id/6003/1/Thesis.pdf.

[17] Ordudari, M. (2007). "Translation Procedures, Strategies and Methods". Online Translation Journal. Volume 11, No. 3. July 2007. pp.15-25. Retrieved October 15, 2015, from http://translationjournal.net/journal/41culture.htm/.

[18] Oxford Advanced Learners Dictionary. (2005). Oxford: University Press.

[19] Pishbin, E. (2011). "A Study of English Translations of Proverbs and Idioms in Two Works by Jamalzadeh: Once upon a Time \& Isfahan is Half the World". (M.A. Paper). Isfahan University. Iran.

[20] Rahekohda, R. (2010). "Expansion in Subtitling: the Case of Three English Movies with Persian Subtitles". M.A. thesis. Isfahan University. Iran.

[21] Ratnan Iningrumg A. (2009). “An Analysis of Slang Expressions Translation in "Mean Girls” Movie.”M.A.Paper. Sebelas Maret University.

[22] Shadrah, N.I. (2010). Translation Analysis of Colloquial Expressions in the Children's Storybook Entitled the Secret Life of MS WIZ by Terence Blacker. M.A. thesis. English Department Faculty of Letter and Fine Arts, Sebelas Maret University. Surakarta. Retrieved May 12, 2016, from https://eprints.uns.ac.id/8190/1/156192308201011261.pdf.

[23] Shiyab, S. (2007). "Synonymy in Translation". Translation Studies Department United Arab Emirates University: UAE. Retrieved May 12, 2015, from translationjournal.net.

[24] Sukspiroj, A. (2009). "A Study of Informal English Language used in the movie "The Holiday". B.A. Paper. Faculty of Liberal Arts: University of Sussex. U.K.

[25] Tverberg, L. (2014). "Speaking is Painting: Why No Translation Can Be Perfect". Retrieved September 15, 2016, from http://ourrabbijesus.com/articles/speaking-painting-bible-translation/.

[26] Ulvydienè, L., Abramovaitėrences, B. (2012). "Literary Style in Translation: Slang in J. D. Salinger's The Catcher in the Rye". Studies about Languages. 2012. NO. 20. ISSN 1648-2824 KALBU STUDIJOS. 2012.20 NR. http://dx.doi.org/10.5755/j01.sal.0.20.1776. pp. 100-108.

[27] Weeks, L. (2010). "Do We Talk Funny? 51 American Colloquialisms". Retrieved May 11, 2016, from http://www.npr.org/sections/.

[28] Zafarghandi, A.M. A \& Falahadoost. (2013). A Comparative Study of English Colloquial Language Utterances in Novel Translation from English to Persian. International Researcher. Vol.2. Issue no. 1 March. pp. 222-239.

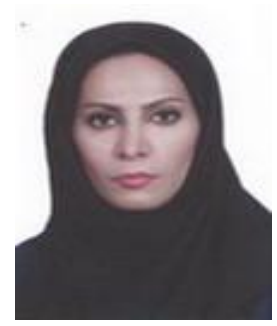

Elham Jalalpour was born in Isfahan, Iran in 1981. She received her M.A. degree in English language translation from Islamic Azad University, Isfahan (Khorasgan) Branch, Iran in 2016.

She is currently a Translator in Isfahan Steel Company. Her interests include language studies, linguistics and commerce. She is an interpreter and translates different documents and contract mostly in the field of technical, commercial and economical texts.

Mrs. Jalalpour took part in several meetings and seminar as an interpreter mostly in the field of commerce (import \& export), metallurgical and technical aspects.

Hossein Heidari Tabrizi was born in Tabriz, Iran in 1969. He received his PH.D. degree in English language teaching from Shiraz University, Iran in 2008.

He is currently Assistant Professor in Islamic Azad University, Isfahan (Khorasgan) Branch, Iran since 1999. His interests include methodology of language teaching, translation \& sociolinguistics.

Dr. Heidari has published several articles and is an author to several publications in the field of pedagogy of teaching, discourse analysis, sociolinguistics, translation studies and language assessment. He is the representative of the university in standard test center of English language and the chairman and associate member of the test center of IELTS. 